Cover Page

\title{
Consent in Body Donation
}

Tom Farsides ${ }^{1 *}$, Claire F. Smith ${ }^{2}$

${ }^{1 *}$ Tom Farsides, School of Psychology, University of Sussex, Brighton, United Kingdom

${ }^{2}$ Claire F. Smith, Department of Medical Education, Brighton and Sussex Medical School, University of Sussex, Brighton, United Kingdom

Running Title: Consent in Body Donation

* Tom Farsides, School of Psychology, University of Sussex, Brighton, United Kingdom, BN1 9QH, United Kingdom. E-mail: t.l.farsides@ sussex.ac.uk

NOTE: This is the authors' version of a paper accepted 13 January 2020 for publication in the European Journal of Anatomy. The published version is likely to differ in minor ways, particularly with respect to formatting. 


\section{SUMMARY}

This article explores potential threats to the validity of consent in body donation and potential responses to such threats. To minimize abstract generalizations, the article draws particularly on United Kingdom regulations but each of the issues it explores is applicable in many countries. Methods used were searches of relevant (e.g., medical ethical) literatures using pertinent search terms (e.g., consent) and discussions with multiple stakeholders (e.g., family members of body donors). The main threats identified were (1) failing to adequately acknowledge relatives' roles in donation, particularly as donation often cannot be completed without relatives' active participation; (2) failing to ensure that donors are informed enough to be able to give valid consent, especially given 'specification' and 'temporality' problems inherent in establishing consent for body donation; and (3) failing to genuinely prioritize donors' motives and concerns during and after obtaining their consent. Possible ways of countering these threats include layering information given and made available to potential donors and having donors consent not to 'donation and anything that might follow' but instead to 'relative-acknowledged donation, selective explicit consent, and delegated decision-making'. The latter involves donors specifying and relatives acknowledging donors' key preferences and prohibitions, among which is nomination or acceptance of specified proxies who may make decisions on donors' behalf after their death. By making such changes, the validity of consent for body donation could be substantially improved in ways that also increase respect for both donors and their autonomy and these changes may also increase the number of completed donations.

Key Words: altruism, body donation, consent, medical education 


\section{INTRODUCTION}

Much medical teaching and research relies heavily on a regular supply of dead bodies and body parts (Smith, 2018). Obtaining donors' informed consent is increasingly thought to be the best available safeguard against unethical body procurement and use (Champney et al., 2018). This is because obtaining valid consent "can render actions morally permissible that would otherwise be wrong" (Grady, 2015, p. 855). This means that certain actions must be considered morally wrong and therefore impermissible unless valid consent is obtained. The validity of consent for any complex matter will always and necessarily be a matter of degree (O’Neill, 2003; Farsides, 2012; Boyd, 2015; Grady, 2015). This paper reviews both the ethical literature concerning requirements for obtaining valid consent and the procedural literature detailing how consent for body donation is currently actually obtained. To avoid vague abstractions, focus is given to the situation in the United Kingdom (UK) but the points made are globally relevant. The review identifies three key threats to obtaining valid consent within current procedures for obtaining consent for body donation. Having identified and explained these threats, the review details promising ways to ameliorate or remove them.

\section{METHOD}

The review was based on searches of anatomical, medical ethical, and psychological academic literatures using such terms as 'consent', 'body donation' and 'posthumous donation'. Issues identified were also considered during discussions with multiple stakeholders, including anatomists, ethicists, and family members of body donors. 


\section{CURRENT UK BODY DONATION}

Teaching and research using donated bodies and body parts is regulated in the UK primarily by the Anatomy Act 1984 (Anatomy Act, 1984) and the Human Tissue Act 2004 (Human Tissue Act, 2004). The regulatory body for the latter is the Human Tissue Authority (HTA) who explicitly state that they prioritize "the fundamental guiding principle of consent" (HTA, 2017). Similar priorities guide regulatory bodies throughout Europe (McHanwell et al., 2008) and beyond (Riederer \& Bueno-López, 2014).

Under the Human Tissue Act 2004, valid consent must be obtained from people while they are alive for their bodies to be used for anatomical examination (including research, surgical practice, etc.) after their death. Only such first-person consent can be accepted. The easiest and most common way for people to register their willingness to become body donors is for them to contact a nearby establishment licensed by the HTA so that they can obtain, complete, and return an appropriate consent form (HTA, 2019), one version of which is shown in Figure 1. Eighteen licensed establishments share a postcode system to accept bodies donated within local geographical regions. In 2008 the number of bodies accepted was around 900 (Smith, 2018). There are more medical schools in the UK than this, but some do not use human bodies for teaching (Heylings 2002; McLachlan et al., 2004). The London Anatomy Office (LAO) coordinates donation across seven medical schools and universities in London and the South East of England (HTA, 2018). The structure of regulation in the UK means that for each institution that holds an HTA license there is a License Holder (a Dean or Pro Vice Chancellor etc.), a Designated Individual (DI) (usually the Head of Anatomy), and then several Persons Designated (PD) (lecturers, and/or technicians who work within the license). The typical lines of reporting are shown in Figure 2. 
Although the HTA provide a template, there is no standard consent form. This means that slight variations exist across consent forms used in different regions. The LAO consent form invites people to consent to their donated bodies being "used for anatomical examination, education, training and research" and some information is provided about what this might and what it will not involve. For example, it might involve bodies being used for "Research in connection with disorders but organs will not be donated for transplantation". All consent forms register how long donors give permission for their body to be retained and whether they consent to images being taken and used for education, training and research. Information included with the LAO consent forms repeatedly advises donors to discuss their donation wishes with their relatives but there is no requirement for them to do so.

\section{ISSUE 1. THE ROLE OF RELATIVES, FRIENDS, EXECUTORS OR SOLICITORS}

Despite there being no requirement for relatives' participation during the consent process, donation is very unlikely to occur without relatives' active participation. This is because various things have to happen after a death to allow donation to occur and several of these things require the voluntary participation of relatives (or others acting on behalf of the deceased although for convenience we will use "relatives" as a catch-all term). Foremost among the requirements placed on relatives is them needing to quickly inform the relevant HTA-authorized institution when a donor dies. If any relatives choose not to do this then an obvious consequence is that donation which otherwise might have occurred definitely will not happen. It is possible that the number of such non-facilitating relatives is substantial. The little evidence which exists suggests that a considerable number of would-be donors do not discuss their donation wishes with their relatives. A study in Turkey revealed that $80 \%$ of people who intended to donate had not discussed at all these intentions with their relatives (Gürses et al., 2018). If donors and their relatives have not explicitly and thoroughly discussed their 
respective preferences and reservations, it seems at least possible that relatives will not facilitate donation in the immediate aftermath of their loved-ones' deaths. This means that procedures to which people have consented and that they may actively desire sometimes (perhaps often) have a considerably reduced chance of being enacted; that bodies otherwise available for donation are sometimes (perhaps often) not actually donated; and that relatives may sometimes (perhaps often) experience avoidable anguish having been put into a position of authority and responsibility without their knowledge and having to make potentially devastatingly difficult decisions without any preparation immediately following the death of someone close to and often loved by them.

Even in otherwise ideal circumstances, there is a long list of factors that can prevent donation, including post-mortem examination, certain infectious diseases, organ donation, exceptional body weight, death during public holidays, and many more. In such circumstances, relatives who expected donation to occur can be shocked and distressed when it does not, and also have to make funeral arrangements that they did not expect would be immediately necessary (Smith, 2018). There is no requirement on the part of donors or LTA-authorized organizations for relatives to be informed prior to donors' deaths about any of these possibilities, still less to give their active consent for the responsibilities that they will have in various circumstances beyond their control.

\section{ISSUE 2. APPROPRIATELY INFORMED CONSENT}

Most everyday acts of consent are for clearly specified things to happen almost immediately and to take place over a relatively delineated period, e.g., as happens when one consents to a phone contract. It is unusual and perhaps unique that consent can be given many years in advance for a relatively poorly specified wide range of possible procedures of unknown 
duration. This is often what happens when people consent to become body donors and thus the consent they give is at increased risk of being invalid as moral permission for many of the procedures that can and do follow the mere act of donation.

The HTA state that for consent to be valid: "it must be given voluntarily, by an appropriately informed person who has the capacity to agree to the activity in question. The person should understand what the activity involves [and] what the material risks are" (HTA, 2017). This immediately raises questions about what "the" activity of consenting to body donation is and what it means for donors to be "appropriately informed" about it.

Beyond consenting to HTA-approved institutions taking possession of their bodies after death, the HTA considers that "consenting to body donation" also entails consenting to "removal, storage and/or use of material" from one's body after death "for any scheduled purpose" (HTA, 2017). It lists among "scheduled purposes" such things as "anatomical examination; ... obtaining scientific or medical information about a deceased person which may be relevant to any other person (including a future person); public display; research in connection with disorders, or the functioning, of the human body; ... education or training relating to human health; [and] performance assessment” (HTA, 2017). The HTA also says that authorized establishments may "charge for providing human tissue to others for training and research, including those working for private companies" and it specifically requires donors to be provided with "easily accessible information about how and why they [i.e., authorized institutions] charge, and to whom they will supply tissue samples" (HTA, 2017). 
Beyond recognizing the range of things that may be done with and to donated bodies, it is also necessary to recognize the range of people who may conduct or witness these procedures. An incomplete list of such people includes anatomists, medical students, dental students, school children, the general public, physiotherapists, surgeons, massage therapists, medical artists, medical engineers, medical researchers, military researchers, technologists, and commercial organizations (Borland \& Condon, 2016; Jones, 2016; Champney et al., 2018; Smith, 2018).

Perhaps in recognition of the wide range of 'sub-activities' that may be subsumed under 'the' activity of consenting to body donation, the HTA insist that for consent to be valid, it is "important to ensure that the consent sought from donors is fully informed" (HTA, 2017). The HTA heavily stresses this point, saying that "When seeking consent ... full and clear information should be provided about the purpose for which consent is being sought.... This information should include the nature of the intended activities and the reasons for them ... Consent is valid only if proper communication takes place and the person has a reasonable understanding of what is being explained to them" (HTA, 2017). Since the legal judgement reached in Montgomery $v$ Lanarkshire Health Board (Scotland) 2015 came into force, a "reasonable understanding" requires that donors need to be provided with enough information to ensure that they know about anything that they or 'any reasonable person' in their position would consider a material risk. This adds another layer of complexity to ensuring valid consent. Especially with the range of possibilities that exists, it does not seem unreasonable that a person with particular beliefs and capabilities might consider one or more of the procedures routinely carried out with donated bodies harmful, e.g., disrespectful, repugnant, ethically unacceptable, or otherwise damaging in some way to them, their legacy, their reputation, or their loved ones (Bach, 2016; Roach, 2003). 
All of the above contribute to what we have called the 'specification problem'. Given the range of possible procedures and events that may follow donation, the number of people who can be involved in them, and the spectrum of things that could be considered unacceptable by a particular donor or a 'reasonable person', it just does not seem possible, and still less practical, to try to inform prospective donors about everything that they need to know to be able to provide fully informed consent for body donation and everything that might follow it.

What we have called the temporality problem is distinct from but nevertheless also contributes to the specification problem. This problem arises because consent for donation is obtained long before donation occurs and longer still before donation-dependent procedures are completed. A donor could register at 18 years of age and die aged 108 and body parts from that donor could then be stored, displayed, and used for 100 years or more after their death, i.e., approximately two centuries after that person gave consent. Even if they were told about all the things that could possibly follow donation that were known about at the time of registration, societal and technological developments will inevitably have occurred in the period following this that enable things to be done with and to their donated bodies that they simply could not have been fully informed about with any specificity at the time that their consent was obtained (Jones, 2007; Cornwall, 2016; Cornwall et al., 2016; Márquez-Grant \& Errickson, 2017; Champney et al., 2018; Gilbert et al., 2018).

A somewhat metaphysical but nevertheless important aspect of the temporality problem is the ‘identity problem'. People's priorities and preferences can change across the life course and people often make decisions for the future on the basis of either what they want in the present or what they (sometimes incorrectly) imagine that they will want in the future. When a person completes an advance directive (e.g., a consent form) to state current wishes for the future, 
they do so with some degree of ignorance about what the future will bring, both in terms of context (e.g., potentially changing practices) but also in terms of personhood (i.e., potential changes in preferences). Because people can be rather poor at accurately anticipating their own future preferences (Wilson \& Gilbert, 2003), and because it is often not safe to assume that someone who neglects to opt out thereby also demonstrates continuing support for something (MacKay, 2015), this means that consent obtained in the past is not always a solid basis for assuming on-going consent and/or consent at some point in the future (Helgesson \& Eriksson, 2011; Horn, 2014; Jongsma, \& van de Vathorst, 2015; Custers, 2016; Stahl and Banja, 2018; Varelius, 2018).

In combination, the specification problem and temporality (including the identity) problem seem to seriously undermine any notion that people can be fully or even adequately informed to give valid consent to 'body donation' as that phrase is currently construed by the HTA, i.e., to encompass both the act of donation itself and all of the many possible procedures that may follow it. Especially since the Montgomery ruling, some fear that authorities will seek consent by providing prospective donors with much more information than they want or could possibly effectively process, e.g., detailed explanations of cost-to-benefit ratios for every possible procedure that might follow donation (Roberts and Indermaur, 2003; Devaney et al., 2018; cf. Berger et al., 2008). Providing prospective donors with an avalanche of often highly technical material is likely to undermine rather than enhance their ability to provide valid consent, let alone their ability to autonomously pursue subjectively important outcomes (Fennell \& Jones, 1992; Gürses et al., 2018). 


\section{ISSUE 3. IDENTIFYING AND SATISFYING DONORS’ DESIRES}

Given the challenges identified above, adequately informed consent might be best pursued by trying to find out what donors particularly want to achieve and to avoid when donating. It might then be possible to tailor procedures to maximally serve donors' interests and at the same time obtain valid consent in ways that acknowledge both the role relatives play and the inherent impossibility of informing donors in detail about everything that might take place after donation.

Empirical evidence suggests that donors are primarily concerned about helping society, their loved ones, or both, although these dominant altruistic desires are often accompanied by a plethora of more idiosyncratic concerns.

Despite the empirical literature being clear that many donors want to be 'generally' helpful or useful, it is often difficult to definitively determine precisely who they wish to help and specifically how. When prospective donors communicate such concerns, they tend to do so in rather vague, broad-brush ways. They say that they want to help mankind, society, the medical profession, or medical students and/or to make positive contributions to knowledge, science, medical research, or medical education and/or to 'avoid waste' (Fennell \& Jones, 1992; Richardson \& Hurwitz, 1995; Bolt et al., 2010; McClea \& Stringer, 2010; Cornwall et al., 2012; da Rocha et al., 2017; Cornwall et al., 2018. See particularly the review included in Gürses et al., 2018). These are not obviously identical concerns. Wanting to play one's part in specific processes likely to "help medical students" (e.g., by providing a body for demonstration or practice of dissection) is not the same thing as being happy for one's body to be used in any way that might conceivably "further science" (e.g., testing weapons' effects). 
Providing even valid consent for one thing does not provide any sort of consent for completely different things.

Beyond having an interest in being 'generally' useful in relatively vaguely specified ways, donors also or instead regularly report being motivated by much more specific desires to help their loved ones, i.e., their close friends, families, and communities. For example, registrants often express an interest in saving their relatives the financial or emotional costs of arranging funerals and attendant ceremonies (Bolt et al., 2010; Cornwall et al., 2018; Gürses et al., 2018). Consenting to procedures anticipated to ease relatives' burdens in particular ways is clearly not the same thing as consenting to practices that might in some way be considered "beneficial to society".

Further, although civic and familial altruism are the most common and perhaps the most motivating of concerns identified by body donors, prospective donors have also reported many additional or alternative concerns. When allowed to identify more than one reason for wanting to become body donors, McClea and Stringer's (2010) 140 registrants gave between them 209 main reasons for bequeathing their body. Among the most common of such concerns that could accompany or replace civic and/or familial altruism were desires to express moral or religious values; to express gratitude for medical help currently or previously received, personally or by a loved one; to donate 'on behalf' of loved others who wanted to but could not personally donate their own bodies; to act as role models for family members and others; to achieve or to be consistent with a perceived sense of meaning, purpose, life-narrative, or reputation; to not be a burden on society, for example when expecting to be survived by no close family members; and to avoid personally unwelcome 
funeral practices (Richardson \& Hurwitz, 1995; Bolt et al., 2010; McClea \& Stringer, 2010; Cornwall et al., 2012, 2018; Gürses et al., 2018).

Notwithstanding some clear commonalities and patterns in donors' stated concerns, it is important to realize that there is no one-to-one correspondence between a donor having a particular motive and them giving or withholding consent for body donation. A desire to make a positive contribution to society after one's death can motivate body donation but it can instead motivate organ donation, a process that in many cases precludes the possibility of body donation. Similarly, a desire to protect loved ones from distress can motivate people to become body donors so that their families are spared the sort of funeral that would otherwise cause them additional expense and misery (Bolt et al., 2010; Cornwall et al., 2018; Gürses et al., 2018). However, it can also prevent people from becoming body donors because they want to allow their families more time with their dead bodies or because they know that their loved ones do not like the idea of what will happen to their bodies post-donation (Şehirli et al., 2004).

One reason that particular motives are neither necessary nor sufficient to ensure or to preclude people giving consent to become a body donor is that people have networks of multiple concerns that interact in complicated ways (Cornwall et al., 2018; Gürses et al., 2018; Olejaz \& Hoeyer, 2016) and these may vary both across individuals (Bohl et al., 2013) and across time and circumstance (Flaskerud, 2017,b). People may have some concerns that push them towards donation and others that inhibit such donation. If people want to both 'help science' and 'avoid family distress', for example, whether or not they become donors may depend on which of these concerns proves to be the stronger, or it may depend on the influence yet 
further reasons pushing the balance one way or the other, e.g., relatives' attitudes towards donation.

In relation to this last point, it is important to note that donors' self-identified concerns can either align with or oppose what they perceive to be others' interests. In the examples above, donors typically wished to 'help medicine' and/or to 'protect their loved ones' (or similar) but there are also examples of donors rejecting or even opposing what they identify to be others' interests, including those of the medical profession (Joraleman, 1995) and those of families (Barbieri, 2018). Thus, with respect to anyone or anything else (e.g., 'medicine', 'science', 'society', 'family', etc.) donors can be altruistic, indifferent, or even antagonistic. That is, particular donors may or may not identify with the perceived interests of particular others and donors can instead or as well have relatively self-focused interests that either align with others' interests or do not, and all of these interests can interact to make it difficult to establish what any particular donor (or 'reasonable person') would want in any given scenario (e.g., with respect to any given procedure).

In summary, body donors have multiple and complex concerns and them giving consent for particular procedures that they expect to follow donation cannot be considered to provide valid consent for all procedures that may follow donation.

\section{POSSIBLE SOLUTIONS}

There are three mutually compatible changes to the current system that seem to offer promise for improving the validity of donor consent while also reaping other benefits such as optimizing donors' and relatives' autonomy, reassuring anatomists and others that their 
procedures are ethically appropriate and in line with donors' wishes, ensuring that maximum numbers of potential donors become actual donors, etc. These are requiring donors to have relatives explicitly witness their consent forms, layering the information that is given and made available to donors and their relatives, and having a number of consent options including giving or withholding general and proxy consent.

Requiring donors to have their closest relatives explicitly witness their donation form is a simple change from current procedures that seems likely to have enormous ethical and practical benefits. This would ensure that donors have the opportunity and the responsibility to discuss their wishes and concerns with relatives, in turn ensuring both that donors are helped and supported to explore morally and familially important issues thoroughly and that relatives are given an opportunity to express any concerns that they may have. The former should improve the quality of first-person consent and the latter should show appropriate respect for relatives' needs, prevent them from being shocked by learning for the first time about their loved ones' donation wishes at about the same time as those loved one's die, and optimize the number of donated bodies that are actually received by LTA-authorized organizations.

Layering information given and made available to donors and their relatives involves initial provision of only the most essential information in the most general terms, plus instructions on how to easily access further, more detailed information. Bunnik et al. (2013) recommend something similar in their "tiered-layered-staged model for informed consent" in personal genome testing. Where appropriate, this could be combined with provisions for donors and their relatives to ask questions and discuss issues, face-to-face or online, with perhaps a 
variety of other people, e.g., medical experts, other donors, relatives of past donors, etc. (cf. Kaye et al., 2013).

Paralleling layered information provision is the possibility of layering consent. Having been provided with basic, essential information, donors could be invited to give "general" consent for anything and everything legal that might follow donation. However, information could also be provided in a way that gave donors an opportunity to learn more and then give explicit consent for and/or explicitly prohibit particular procedures or possibilities, e.g., ones developed after they gave consent or after they died. Additionally or alternatively, donors might be given options to explicitly declare values and concerns particularly important to them, such as "furthering medical knowledge", "assisting medical education", "acting in accordance with my religious beliefs", or similar. This would allow specific donors' specific wishes to be taken into account when deciding after their deaths if their consent could be justifiably assumed for particular procedures that perhaps were not even imaginable at the time they gave consent. In line with this, donors could be asked if they wanted or were willing to explicitly accept or nominate someone to make selected decisions 'in their interests' and 'on their behalf' after their own deaths. This could be a specific person, such as a relative or a medical school's Designated Individual, but it could instead be a group of people analogous to an ethics committee (Coggon et al., 2008; Farsides, 2012; Boyd, 2015; Sulmasy \& Sulmasy, 2015; Gürses et al., 2018). These stewards would then try to make optimal decisions taking all relevant factors into consideration, including protecting the best interests of the deceased in light of all the information at their disposal. One advantage of consensus rather than individual proxy decisions is that the former may help avoid decisions being too heavily weighted by particular points of view, e.g., that of donors who registered their consent long in the past, relatives with strong but perhaps excessively self-serving views, or experienced 
anatomists whose training and practice have altered the ways that they think about bodies and what it is appropriate to do to them; Segal, 1988; O’Neill, 1988; Joralemon, 1995; Delaney et al., 1996; Sanner, 1997; Moreton, 1999; Corrigan, 2003; Şehirli et al., 2004; O’Neill, 2013; Boyd, 2015; Winkelmann, 2016; Hall \& van Niekerk, 2017; Olejaz, 2017; Shaw, 2017; Champney et al., 2018; Cooper, 2018).

\section{DISCUSSION}

A review of both the ethical literature concerning valid consent and UK recommendations about required and best practices when obtaining consent for body donation resulted in identification of three serious issues. First, body donors' relatives are integral to and likely greatly affected by the process of body donation but play no required role in the process of establishing consent. This means that relatives are at least sometimes likely to be placed in distressing situations and react in ways detrimental both to the implementation of donors' wishes and to an optimal supply of donated bodies. Second, consent is currently established using processes that are very unlikely to ensure that donors are fully or perhaps even adequately informed about the range of things that they are in practice giving consent to happen in the period during which medical school officials are responsible for what happens to their bodies and body parts. Third, the same processes of establishing consent (i.e., donors' permissions) do little or nothing to establish donors' preferences (i.e., their concerns). This severely restricts the possibility of establishing whether particular donors provided valid consent for (or indeed may have been enthusiastically in favor of) particular procedures that donors may not have realised were possibilities, e.g., because they were developed only after the donors died. 
The review also suggests that several relatively small changes could be made to procedures for obtaining consent that seem likely to have several relatively large positive effects. Such changes would be to include relatives in the process of establishing donor consent (and possibly obtain relatives' consent at the same time); to provide prospective donors with essential information in 'digestible' ways while also making it easy for them to obtain more detailed information if they chose to do so; and to enable donors to both opt-in and opt-out of particular practices as well as to designate authorities to make further decisions 'on their behalf' after the donors' own deaths. Each of these small changes seems likely to considerably improve the validity of donors' consent as well as promote other ethical and practical benefits, not least enhancing donors' autonomy and increasing the number of bodies that are actually donated. For all these reasons, we recommend that the following provisional recommendations are given serious consideration by everyone who is interested in optimizing the validity of donor consent.

\section{RECOMMENDATIONS}

1. Donors should have their closest relative formally witness their consent forms.

2. Information provided to donors and relatives should be layered. Initial provision should include only essential, general information plus simple and clear instructions on how to easily get more.

3. Donors should be able to explicitly give or withhold consent for a variety of options, from general consent to all procedures thought suitable by an anatomist to specific consent for particular procedures and/or to delegate or accept particular proxy decision makers.

4. As much as possible should be established about what donors want to achieve from their donation and about what they specifically want to avoid. This may be 
accomplished via a combination of research into particular populations' preferences and by individualized declarations made by particular donors.

5. When the consent explicitly given by donors cannot safely be assumed for specific procedures, people deciding whether consent may nevertheless be safely assumed should take into account all information at their disposal, including donors' specified wishes and fears, where available.

\section{ACKNOWLEDGEMENTS}

The authors wish to thank Ms. Kim Claridge at the London Anatomy Office (LAO) for checking the factual accuracy of material related to the LAO. 


\section{REFERENCES}

ANATOMY ACT (1984) The National Archives, London UK URL:

https://www.legislation.gov.uk/ukpga/1984/14/contents [accessed 2 March 2019].

BACH MC (2016) Still human: A call for increased focus on ethical standards in cadaver research. HEC Forum, 28: 355-367.

BARBIERI A (2018) Our mother wants to donate her body and we don't want her to. The Guardian, London UK URL:https://www.theguardian.com/lifeandstyle/2018/oct/12/motherwants-to-donate-body-we-dont-want-her-to [accessed 12 October 2018].

BERGER O, GRØNBERG BH, SAND K, KAASA S, LOGE JH (2008) The length of consent documents in oncological trials is doubled in twenty years. Ann Onc, 20: 379-385.

BOHL M, HOLMAN A, MUELLER DA, GRUPPEN LD, HILDEBRANDT S (2013) The willed body donor interview project: Medical student and donor expectations. Anat Sci Educ, 6:90-100.

BOLT S, VENBRUX E, EISINGA R, KUKS JB, VEENING JG, GERRITS PO (2010)

Motivation for body donation to science: More than an altruistic act. Ann Anat,192:70-74.

BORLAND C, CONDON B (2016) Circles of Focus [Show/Exhibition]. Glasgow, UK. URL: http://www.cca-glasgow.com/archive/christine-borland--brody-condon--circles-of-focus [accessed 25 February 2019]. 
BOYD K (2015) The impossibility of informed consent? J Med Ethics, 4:44-47.

BUNNIK EM, JANSSENS ACJ, SCHERMER MH (2013) A tiered-layered-staged model for informed consent in personal genome testing. Eur J Hum Gen, 21:596.

CHAMPNEY TH, HILDEBRANDT S, GARETH JONES D, WINKELMANN A (2018)

BODIES R US: Ethical views on the commercialization of the dead in medical education and research. Anat Sci Educ. Early View https://doi.org/10.1002/ase.1809

COGGON J, BRAZIER M, MURPHY P, PRICE D, QUIGLEY M (2008) Best interests and potential organ donors. BMJ, 336:1346-1347.

COOPER J (2018) Organs and organisations: Situating ethics in organ donation after circulatory death in the UK. Soc Sci Med, 209:104-110.

CORNWALL J (2016) The ethics of 3D printing copies of bodies donated for medical education and research: What is there to worry about? Australas Med J, 9:8-11.

CORNWALL J, CALLAHAN D, WEE R (2016) Ethical issues surrounding the use of images from donated cadavers in the anatomical sciences. Clin Anat, 29:30-36.

CORNWALL J, PERRY GF, LOUW G, STRINGER MD (2012) Who donates their body to science? An international, multicenter, prospective study. Anat Sci Educ, 5:208-216. 
CORNWALL J, POPPELWELL Z, MCMANUS R (2018) “Why did you really do it?” A mixed-method analysis of the factors underpinning motivations to register as a body donor. Anat Sci Educ, 11:623-631

CORRIGAN O (2003) Empty ethics: The problem with informed consent. Sociol Health Illn, 25:768-792.

CUSTERS B (2016) Click here to consent forever: Expiry dates for informed consent. Big Data Soc, 3(1). https://doi.org/10.1177/2053951715624935

DA ROCHA AO, DE CAMPOS D, FARINA MA, PACINI GS, GIROTTO MC., HILBIG A (2017) Using body donor demographics to assist the implementation of donation programs in Brazil. Anat Sci Educ, 10:475-486.

DELANEY L, MONTH S, SAVULESCU J, BROWETT P, PALMER S (1996) Altruism by proxy: Volunteering children for bone marrow donation. BMJ, 312:240-243.

DEVANEY S, PURSHOU, C, CAVE E, HEYWOOD R, MIOL, J, REINACH N (2018) The far-reaching implications of Montgomery for risk disclosure in practice. J Patient Saf Risk Manag, Early View https://doi.org/10.1177/2516043518811501

FARSIDES B (2012) Respecting wishes and avoiding conflict: Understanding the ethical basis for organ donation and retrieval. Br J Anaesth, 108:i73-i79. 
FENNELL S, JONES DG (1992) The bequest of human bodies for dissection: A case study in the Otago Medical School. N Z Med J, 105:472-474.

FLASKERUD JH (2017a) Individual and dynamic: Western views of a good death. Issues Ment Health Nurs, 38:865-868.

FLASKERUD JH (2017b) Non-Western perspectives of a good death. Issues Ment Health Nurs, 38:763-766.

GILBERT F, O’CONNELL CD, MLADENOVSKA T, DODDS S (2018) Print me an organ? Ethical and regulatory issues emerging from 3D bioprinting in medicine. Sci Eng Ethics, 24:73-91.

GRADY C (2015) Enduring and emerging challenges of informed consent. $N$ Engl J Med, 372: 855-862.

GÜRSES İA, ERTAŞ A, GÜRTEKIN B, COŞKUN O, ÜZEL M, GAYRETLI Ö, DEMIRCI MS (2018) Profile and motivations of registered whole-body donors in Turkey: Istanbul University experience. Anat Sci Educ, Early View https://doi.org/10.1002/ase.1849

HALL DR, VAN NIEKERK AA (2017) Reconsidering counselling and consent. Dev World Bioeth, 17:4-10.

HELGESSON G, ERIKSSON S (2011) Does informed consent have an expiry date? A critical reappraisal of informed consent as a process. Camb Q Healthc Ethics, 20:85-92. 
HEYLINGS DJ (2002) Anatomy 1999-2000: The curriculum, who teaches it and how? Med Educ, 36:702-710.

HORN R (2014) “I don’t need my patients' opinion to withdraw treatment”: Patient preferences at the end-of-life and physician attitudes towards advance directives in England and France. Med Health Carre Philos, 17:425-435.

HTA (2019) Donating your body. Human Tissue Authority, London, UK. URL: https://www.hta.gov.uk/donating-your-body [accessed 24 May 2019]

HTA (2018). London Anatomy Office - Medical school. Human Tissue Authority. https://www.hta.gov.uk/medical-schools/london-anatomy-office [accessed 24 May 2019]

HTA (2017) Code A: Guiding principles and fundamental principle of consent: Code of practice. Human Tissue Authority, London, UK. URL: https://www.hta.gov.uk/hta-codespractice-and-standards-0 [accessed 24 May 2019]

HUMAN TISSUE ACT (2004) The National Archives, London, UK. URL: https://www.legislation.gov.uk/ukpga/2004/30/contents [accessed 2 March 2019].

JONES DG (2016) Searching for good practice recommendations on body donation across diverse cultures. Clin Anat, 29:55-59. 
JONES DG (2007) Anatomical investigations and their ethical dilemmas. Clin Anat, 20:338343.

JONGSMA KR, VAN DE VATHORST S (2015) Dementia research and advance consent: It is not about critical interests. J Med Ethics, 41:708-709.

JORALEMON D (1995) Organ wars: The battle for body parts. Med Anthropol Q, 9:335-356.

KAYE J, WHITLEY EA, LUND D, MORRISON M. TEARE H, MELHAM K (2015) Dynamic consent: a patient interface for twenty-first century research networks. Eur J Hum Gen, 23:141.

MACKAY D (2015) Opt-out and consent. J Med Ethics, 41:832-835.

MCCLEA K, STRINGER MD (2010) The profile of body donors at the Otago School of Medical Sciences-Has it changed? N Z Med J, 123:9-17.

MÁRQUEZ-GRANT N, ERRICKSON D (2017) Ethical considerations: An added dimension. In T. Thompson \& D. Errickson (Editors). Human Remains: Another Dimension: The Application of Imaging to the Study of Human Remains. Academic Press. P193-204.

MCHANWELL S, BRENNER E, CHIRCULESCU ARM, DRUKKER J, VAN MAMEREN H, MAZZOTTI G, PAIS D, PAULSEN F, PLAISANT O, CAILLAUD MM, LAFORET E, RIEDERER BM, SANUDO JR, BUENO-LOPEX JL, DONATE-OLIVER F, SPRUMONT P, TEOFILOVSKI-PARAPID G, MOXHAM BJ (2008) The legal and ethical framework 
governing Body Donation in Europe- A review of current practice and recommendations for good practice. Eur J Anat, 12:1-24.

MCLACHLAN JC, BLIGH J, BRADLEY P, SEARLE J (2004) Teaching anatomy without cadavers. Med Educ, 38:418-424.

MORETON C (1999) Doctors think it's fine to use organs from dead children for research and training; grieving parents are horrified. The gulf between public expectation and medical practice has never been wider. The Independent, London UK

URL:https://www.independent.co.uk/life-style/health-and-families/health-news/why-didprofessor-dick-van-velzen-think-butchering-babies-was-right-738078.html [accessed 5 December 2018].

OLEJAZ M (2017) When the dead teach. Exploring the postvital life of cadavers in Danish dissection labs. Med Anth Theory, 4: 125-149.

OLEJAZ M, HOEYER K (2016) Meet the donors: A qualitative analysis of what donation means to Danish whole body donors. Eur J Anat, 20:19-29.

O’NEILL O (2013) Responses. In: D. Archard, M. Deveaux, N. Manson, D. Weinstock (Editors), Reading Onora O'Neill. Abingdon, Oxon. Routledge. p 229-25.

O’NEILL O (2003) Some limits of informed consent. J Med Eth, 29: 4-7.

O’NEILL P (1988) Negotiating consent in psychotherapy. NYU Press. 
RIEDERER BM, BUENO-LÓPEZ JL (2014) Anatomy, respect for the body and body donation - a guide for good practice. Eur J Anat, 18: 361-368.

RICHARDSON R, HURWITZ B (1995) Donors' attitudes towards body donation for dissection. The Lancet, 346:277-279.

ROACH M (2003) Stiff. The curious lives of human cadavers. London: Penguin.

ROBERTS L, INDERMAUR D (2003) Signed consent forms in criminological research: Protection for researchers and ethics committees but a threat to research participants? Psychiatr Psychol Law, 10:289-299.

SANNER MA (1997) Encountering the dead body: Experiences of medical students in their anatomy and pathology training. Omega, 35:173-191.

SEGAL DA (1988) A patient so dead: American medical students and their cadavers. Anthropol Q, 61:17-25.

ŞEHIRLİ ÜS, SAKA E, SARIKAYA Ö (2004) Attitudes of Turkish anatomists toward cadaver donation. Clin Anat, 17:677-681.

SHAW RM (2017) Bioethics beyond altruism. In: Bioethics beyond altruism. Palgrave Macmillan, Cham. P 3-13. 
SMITH CF (2018) The silent teacher: The gift of body donation. $1^{\text {st }}$ Ed. Storrington, UK:

Anatomically Correct. P16-31.

STAHL D, BANJA J (2018) The persisting problem of precedent autonomy among persons in a minimally conscious state: The limitations of philosophical analysis and clinical assessment. AJOB Neurosci, 9:120-127.

SULMASY DP, SULMASY LS (2015) On substituted arguments. J Med Ethics, 41:732-733.

VARELIUS J (2018) Advance directives and the descendant argument. HEC Forum, 30:1-11.

WILSON TD, GILBERT DT (2003) Affective forecasting. Adv Exp Soc Psychol, 35:345-411.

WINKELMANN A (2016) Consent and consensus - ethical perspectives on obtaining bodies for anatomical dissection. Clin Anat, 29:70-77. 
FIGURE 1: London Anatomy Office (LAO) Consent Form

Part A: Donor's Details - To be completed in BLOCK CAPITALS

Title Surname/family name

Forename(s)

Address

Postcode Tel no

Date of birth Religion/faith group (if applicable)

\section{WISH TO DONATE MY BODY AFTER MY DEATH. I UNDERSTAND THAT IT MAY BE USED FOR ANATOMICAL EXAMINATION, EDUCATION, TRAINING AND RESEARCH.}

\section{Part B: Consent - Please tick as appropriate}

1. I do not place any restriction on the length of time that my body or body parts may be retained

OR

$\square$ My body can be retained for a maximum of 3 years and

a. $\quad$ Parts of my body may be retained upon conclusion of anatomical examination for longer than 3 years

b. $\square$ No part of my body may be retained upon conclusion of anatomical examination

2. I consent to images being taken of my body or body parts. I understand that they will be used for education, training and research and that I will not be identifiable in these images.

Part C: Witness Details

Full Name

Address

Postcode Relationship to donor

Part D: Signatures - To be signed and dated at the same time in each other's presence

Signature of donor Date

Signature of witness Date

Complete both forms. Return one copy to the London Anatomy Office and keep the other with your Will or legal papers. If you would like to receive a donor card please enclose a stamped addressed envelope. 